\title{
A reforma das relações sindicais volta ao debate no Brasil
}

\author{
Clemente GANZ LÚCIO ${ }^{I}$
}

\begin{abstract}
1
S RELAÇÕES sindicais estão novamente em debate no Congresso Nacional, com propostas para promover reformas por iniciativa do Poder Executivo e por parte dos parlamentares que buscam dar tratamento legislativo colocar o assunto nas várias Comissões das duas casas, Câmara dos Deputados e Senado Federal. Neste artigo recuperaremos brevemente a história desse debate, apontaremos as iniciativas recentes da reforma sindical, situaremos como está pautado o assunto e indicaremos princípios e diretrizes que tem pautado o movimento sindical de trabalhadores nesse processo.
\end{abstract}

\section{Relações sindicais: do que trata?}

As relações sociais de produção econômica de bens e serviços, em uma economia de mercado capitalista, colocam trabalhadores e empregadores em situação de cooperação com interesses opostos nos resultados apropriados - salários e lucros - e que se traduzem em diversos tipos de conflitos gerais e específicos.

Ao longo da história os trabalhadores atuaram e realizaram lutas coletivas para expressar seu posicionamento ante os conflitos distributivos materializados em salário, jornada e condições de trabalho, saúde e segurança, proteção social e previdenciária, entre outros, bem como buscaram construir soluções e promoverem mudanças nas situações específicas e gerais. Ao surgirem os sindicatos vão adquirindo a forma de expressão organizativa dos trabalhadores, que buscam atuar coletivamente e de maneira solidária na expressão propositiva de suas demandas e projetos, no campo das questões do mundo do trabalho e da sua proteção laboral. Os empregadores também constituem suas organizações.

Uma das dimensões constitutivas do Estado moderno é trazer para a institucionalidade das democracias, nos contextos históricos específicos, a organização sindical, a formalização de instrumentos e regras para tratar dos conflitos no mundo do trabalho, o estabelecimento de procedimentos para mediar interesses, favorecendo que a representatividade de interesses seja capaz de pactuar regras para regerem as relações sociais de produção.

No pós-guerra se reestruturou o sistema sindical nos países da Europa, passando esse a compor a base política da socialdemocracia que buscava promover a coesão social naquele território. Uma economia de mercado regularia as relações sociais de produção pela mediação de interesses com equilíbrio de força entre capital e trabalho, com proteção da atividade sindical e com medidas 
contra práticas antissindicais. Formação de um sistema sindical que favoreceria negociações para arranjos de sistemas nacionais de contratação coletiva, de maneira diversa articulados desde o local de trabalho, passando pelo nível setorial e chegando ao nacional. Um sistema tributário progressivo geraria receita para um Estado Social desenvolver políticas públicas universais garantidoras de igualdade de oportunidade e, algumas vezes, de igualdade de condição. Em outros países, como Estados Unidos e Japão especialmente, estruturou-se um sistema sindical focado na regulação no âmbito da empresa. Nos Estados Unidos um sistema que estimula a disputa entre trabalhadores e empregados sobre a oportunidade de estabelecer a regulação salarial por meio da representação coletiva. No Japão, um sistema que estimula um tipo forte de pactuação pulverizada por empresa.

No Brasil a institucionalidade das relações sindicais foi formalizada no Estado Novo, na década de 1940, quando o governo Vargas edita o Decreto-Lei n.5.452 de 10 de maio de 1943, com o qual cria a Consolidação das Leis do Trabalho (CLT). Nele estão expressos direitos trabalhistas e obrigações dos empregadores para com as relações laborais e condições de trabalho e salário; é instituído o sistema sindical confederativo de representação dos interesses profissionais com os sindicatos, federações (reunião de sindicatos) e confederações (reunião de federações) de trabalhadores, e a representação espelhada do interesse econômico, a estrutura sindical dos empregadores; define as regras para as negociações, a maneira como se formalizam os acordos e convenções coletivas; são criados mecanismos de solução de conflito, em especial a Justiça do Trabalho e a maneira de tratar a greve e o lockout.

Na Constituição de 1988 o sistema sindical foi renovado, e confirmado, como elemento estruturante de um sistema de relações de trabalho recepcionado pelo Estado e por ele estimulado, inclusiva para os servidores públicos.

\section{Reforma sindical no Brasil pós 1988}

A Constituição de 1988 consagrou o sistema sindical para organizar a representação dos interesses dos trabalhadores nos setores privado e público. Desde então os servidores públicos vieram transformando as associações de servidores em sindicatos. Os trabalhadores do setor privado passaram a recuperar e sofisticar a sua organização sindical de base, investiram no aprimoramento da estrutura vertical (federações e confederações), avançando para criarem as Centrais Sindicais, uma organização de nível superior.

As negociações coletivas ganharam dinâmicas em todo o território e setores econômicos, assim como os servidores públicos passaram a demandar a formalização do direito de negociação coletivo no âmbito do direito administrativo.

Diferentes experiências foram se estruturando com sistemas de relações de trabalho que passaram a valorizar a negociação, inclusive sem a intervenção da Justiça do Trabalho, como no caso da negociação nacional dos bancários com os bancos, estruturando diferentes âmbitos e unidades de negociação setorial. 
Em 1993, o ministro Walter Barelli, no governo Itamar Franco, articulou e realizou o "Fórum Nacional sobre Contrato Coletivo e Relações do Trabalho no Brasil". ${ }^{1}$ Os debates indicaram os problemas do sistema sindical e de negociação coletiva, assim como destacaram suas virtudes. Há um claro indicativo presente nos debates de que é necessário investir no fortalecimento da representatividade das entidades, estimular a negociação coletiva, avançar na maior autonomia das partes para a solução dos conflitos em relação à Justiça do Trabalho, promover o direito de organização, bem como qualquer processo de mudança deve prever um período de transição que favoreça a modernização pretendida.

Dez anos depois, em 2003, foi instalado, no governo Lula, o "Fórum Nacional do Trabalho", composto por representações dos empregadores, dos trabalhadores e do Estado e coordenado pelo Ministério do Trabalho e Emprego. Durante dois anos, em mais de 500 horas de negociação em mesas tripartites, em mais outras centenas de horas em reuniões bilaterais e por bancada, foi elaborado um projeto de reforma sindical que buscava estruturar e organizar uma reforma no sistema sindical e de relações de trabalho, a partir do qual se daria o aprimoramento da legislação trabalhista. Esse processo fundamentava-se no fortalecimento da representatividade das entidades sindicais, que assumiriam progressivamente mais responsabilidades com processos negociais incentivados e ampliados. O direito de negociação coletiva no setor público seria regulamentado. Mecanismos ágeis e seguros para a solução de conflitos, direito de greve, complementariedade voluntária entre o negociado e o legislado foram diretrizes materializadas no projeto. Novas regras para a organização sindical e seu financiamento visavam fortalecer as representações e criar condições para sua atuação. Um plano de transição visava gerar segurança para a realização das mudanças.

O acordo político pressupunha que a reforma sindical e do sistema de relações de trabalho antecederiam a reforma trabalhista, porque o novo modelo sindical e de negociação resultante da reforma proporcionaria os elementos para o contorno das mudanças na CLT, especialmente no que se refere à delimitação entre o legislado e o negociado, e à transição incentivada e voluntária da situação presente para a futura.

Esse projeto foi materializado na Proposta de Emenda Constitucional PEC 369/2005 e uma proposta de Lei Complementar apresentadas pelo Poder Executivo em 4.3.2005. ${ }^{2}$

O projeto parou no Congresso Nacional na crise de 2005, nas disputas internas no mundo sindical de empregadores e de trabalhadores e nas múltiplas resistências às mudanças.

Com a Lei n.11.648/2008, estabeleceu-se o reconhecimento das centrais sindicais, organizações que passaram a compor o sistema sindical com a prerrogativa de representação geral dos trabalhadores.

Quase dez anos depois, em junho de 2017, o Legislativo e Executivo transformaram profundamente a legislação trabalhista brasileira e o sistema de 
relações de trabalho com a Lei n.13.467/2017, a chamada reforma trabalhista. Meses antes, em março, a Lei n.13.429/2017 promoveu a liberação geral da terceirização no setor privado e público.

Essa reforma alterou a hierarquia normativa em que Constituição, legislação, convenções e acordos coletivos eram pisos progressivos de direitos. A partir de então, a Constituição passou a ser o teto, a legislação, uma referência de direitos que podem ser reduzidos pelas convenções; os acordos coletivos celebrados no âmbito da empresa podem diminuir garantias previstas nas leis e nas convenções; também foi dado ao indivíduo o poder de abrir mão de direitos conquistados coletivamente, dar quitação definitiva de verbas rescisórias. Os trabalhadores e os sindicatos "ganharam o livre direito" de reduzir salários e garantias, flexibilizar contratos, ampliar ou reduzir jornada e quitar definitivamente direitos - na presença coercitiva do empregador. $\mathrm{O}$ acesso dos trabalhadores à Justiça do Trabalho foi limitado. As empresas passaram a ter inúmeros instrumentos para garantir máxima proteção e liberdade jurídica para ajustar o custo do trabalho.

Vários novos tipos de contratos foram introduzidos com as mudanças na legislação - tempo parcial, trabalho temporário, intermitente, autônomo exclusivo, terceirizado sem limite, teletrabalho, trabalho em casa -, formas contratuais que permitem ajustar o volume de trabalho à produção no dia, na semana, no mês, ao longo do ano. Esses contratos podem ter ampla flexibilização da jornada no que se refere à duração, intervalos, férias, banco de horas etc. As definições do que é salário foram alteradas e os valores podem ser reduzidos, assim como outras obrigações legais. A demissão foi facilitada, inclusive a coletiva, com diversas formas de quitação definitiva de débitos trabalhistas.

O poder de negociação dos sindicatos vem sendo fragilizado com o "novo poder" de reduzir direitos, por meio da interposição de comissões de representação dos trabalhadores, nas quais é proibida a participação sindical, ou do empoderamento do indivíduo para negociar diretamente. Essas medidas quebram o papel sindical de escudo coletivo e protetor. Como já ocorre em outros países que adotam mecanismos semelhantes, os trabalhadores são incentivados e estimulados, por meio de inúmeras práticas antissindicais e de submissão patronal, a não apoiar ou financiar os sindicatos. Ficarão submetidos ao poder das empresas, pressionados para aceitar acordos espúrios diante do medo de perder o emprego, ainda mais em uma situação de altas taxas de desemprego de longa duração.

A Justiça do Trabalho, que passou a ser paga, terá as tarefas reduzidas à análise formal dos pleitos. A lei criou uma tabela que precifica o ônus da empresa até, no máximo, 50 vezes o salário do trabalhador! ${ }^{3}$

Ao todo foram alterados 117 artigos e outros 200 dispositivos da Consolidação das Leis do Trabalho impactados, movimento que operou um verdadeiro ataque aos direitos laborais e sindicais dos trabalhadores. ${ }^{4}$ 


\section{Reforma trabalhista no mundo}

As reestruturações institucionais avançaram desde 2008 nos países desenvolvidos e em desenvolvimento, sendo uma delas a reforma da legislação e do sistema de relações de trabalho. O objetivo é reduzir o custo do trabalho; criar a máxima flexibilidade de alocação da mão de obra, com as mais diversas formas de contrato e ajustes da jornada; reduzir ao máximo a rigidez para demitir e minimizar os custos de demissão sem acumular passivos trabalhistas; restringir ao limite mínimo as negociações e inibir contratos ou convenções gerais em favor de acordos locais realizados com representações laborais controladas; e quebrar os sindicatos.

As reformas das instituições dos sistemas de relações de trabalho e da legislação trabalhista foram realizadas por mais de uma centena de países depois da crise internacional. A Organização Internacional do Trabalho (OIT) publicou um estudo (Drivers and effects of labour market reforms: Evidence from a novel policy compendium), produzido pelos pesquisadores Dragos Adascalieti e Clemente Pignatti Morano, sobre reformas legislativas laborais e de mercado de trabalho em 110 países, promovidas no período de 2008 a 2014. A pesquisa atualiza investigações anteriores e se utiliza, para a análise, de informações de estudos do Fundo Monetário Internacional (FMI), Banco Mundial e da Organização para a Cooperação e Desenvolvimento Econômico (OCDE). ${ }^{5}$

Em grande parte dos projetos de reforma implementados, duas dimensões são atingidas com maior ou menor intensidade: mercado de trabalho e negociação coletiva. Nos países desenvolvidos predominam iniciativas para reformar a legislação que regulamenta o mercado de trabalho no que se refere aos contratos permanentes. Já nos países em desenvolvimento, a ênfase é maior em reformas das instituições relativas à negociação coletiva. Os autores concluíram que a maioria das remodelagens rebaixou o nível de regulamentação existente e teve caráter definitivo.

Os dados trabalhados pelos autores mostram 642 mudanças na legislação, em 110 países, entre 2008 e 2014. As reformas atingem seu pico, em número, até 2012, na primeira fase da crise, e decrescem até 2014, quando voltam ao nível pré-crise. Para o conjunto dos países investigados, a maior parte das alterações $(55 \%)$ teve o sentido de reduzir a proteção legal; foi implantada em bases permanentes (92\%); e endereçada ao conjunto da população (69\%). Deve-se esclarecer, contudo, que o resultado referente ao sentido das reformas deve-se, basicamente, às medidas implementadas nos países desenvolvidos, maioria do painel analisado $(70 \%)$ e nos quais prevaleceram regras para redução da proteção (66\%). Nos países em desenvolvimento, ao contrário, predominou o reforço da proteção por intermédio da legislação. Em vários desses, a mudança legal centrou-se na criação de instituições para a negociação coletiva, como Angola, Camarões e Gabão ou no reforço aos direitos sindicais, como Bolívia e Colômbia. 
Os resultados do estudo ${ }^{6}$ mostram os impactos sobre o emprego, grande objetivo para justificar as inciativas. Observou-se que países que estão implantando medidas de austeridade fiscal e com regime de câmbio fixo são mais propensos à sua implementação. As variáveis ano eleitoral, ideologia política do governo e PIB per capita não apresentam efeito expressivo na introdução das reformas.

Para a análise dos impactos de curto prazo das reformas, os autores utilizam as mudanças na taxa de desemprego como variável dependente e observam que as medidas adotadas para a regulação do mercado de trabalho não apresentaram efeito significativo sobre o desemprego, seja para o conjunto de países, seja para os subgrupos "desenvolvidos" e "em desenvolvimento".

Ao considerar o ciclo econômico em que as medidas são implantadas, o estudo revela que, no conjunto dos países analisados e no grupo "desenvolvidos", há resultados negativos de curto prazo sobre o emprego quando as mudanças ocorrem em período de contração da economia; já em períodos de estagnação ou crescimento, não se observam impactos. Nos países em desenvolvimento, independentemente do ciclo econômico, não se verifica rebatimento sobre o emprego.

Em resumo, o estudo conclui que: (a) a aprovação de reformas está positivamente associada aos níveis e alterações das taxas de desemprego, indicando que resultados ruins no mercado de trabalho parecem levar ou facilitar os governos a promover reformas na legislação trabalhista; (b) países que passam por processos de consolidação fiscal, por meio da adoção de políticas de austeridade e tem um regime cambial de taxas fixas - caso dos países da União Europeia, com moeda única e política monetária estabelecida pelo Banco Central Europeu - têm maior probabilidade de realizar reformas trabalhistas; (c) no que se refere aos impactos de curto prazo das reformas, nem o aumento, nem a redução da regulação parecem ter impacto sobre a taxa de desemprego; (d) contudo, em situações de crise, a redução da regulação tem um efeito de curto prazo negativo, resultado observado para o conjunto dos países e para os países desenvolvidos.

Do total de reformas que diminuíram os níveis de regulação $74 \%$ trataram de jornada de trabalho, $65 \%$, de contratos de trabalho temporário, $62 \%$, de demissões coletivas, $59 \%$, de contratos permanentes, $46 \%$, de negociações coletivas e $28 \%$, de outras formas de emprego.

\section{Transformações no mundo do trabalho}

O mundo do trabalho vem sendo impactado de maneira multidimensional. Novas tecnologias promovem mudanças disruptivas na oferta de energia, nas possibilidades comunicação e nas formas de transporte, criando condições inéditas para uma nova concepção e estruturação de cadeias e arranjos produtivos, novas estratégias logísticas e localizacionais das empresas. Todos os setores econômicos estão sendo impactados em velocidade acelerada o que faz surgir novos empregos e, de maneira mais intensa, destrói muito mais postos de trabalho. 
Fusões e aquisições fazem as empresas transitarem para novos proprietários, acionistas reunidos em fundos de investimento, ávidos pelo máximo lucro no curto prazo. A lógica da reprodução da riqueza financeira preside e orienta a produção de bens e serviços com novas dinâmicas produtivas e métodos de gestão. As estratégias de negócio e a gestão da força de trabalho têm novos objetivos, diferentes daqueles que estruturaram o sistema de relações de trabalho, a geração de empregos e a partilha de resultados nas últimas décadas. Aumenta a pressão por mudanças para reduzir ou restringir o poder dos sistemas de negociação.

As diferentes formas de terceirização passam a serem usadas em larga escala, no setor privado e público, como forma de externalizar riscos e custos. Uma força de trabalho crescentemente fracionada em múltiplas empresas e formas de ocupação não encontra resposta sindical adequada para essa nova situação.

As grandes empresas estão mudando a estrutura e a organização do sistema produtivo, integrando produção, serviços e comércio, interligando no mundo sua logística em uma unidade global de gestão que opera sem parar. As relações de dependência e submissão das pequenas e médias empresas aumentam, com pressões de todas as ordens. Os trabalhadores vivem no cotidiano das relações de trabalho todas essas mudanças e as pressões aumentam e se diversificam trazendo impactos inéditos para a saúde, jornadas extensas e flexíveis destroem o convívio familiar e social, pressões, perdas e estresse conduzem ao alívio através do uso de drogas.

A inteligência artificial e a internet geram a possibilidade, em velocidade alucinante, de as máquinas ocuparem cada vez mais espaços nas atividades produtivas e de transformar em produto econômico todas as atividades humanas. A industrialização com inteligência artificial do setor de serviços transforma, potencialmente, todas as atividades humanas em produtos econômicos (oferta) e em consumo (demanda). Empregos com bons salários e os melhores postos de trabalho, especialmente da indústria, são eliminados e surgem novas ocupações no setor de serviços, trabalhadores uberizados, assistentes, auxiliares e serventes, precários, flexíveis, inseguros e mal remunerados.

Rapidamente as atividades laborais passam a ser mediadas ou assistidas por máquinas e inteligência artificial. De maneira crescente e ampliada as máquinas passam a executar as atividades laborais e os humanos passam a ser auxiliares. Emprego, ocupação, profissão e postos de trabalho mudarão várias vezes ao longo da vida laboral.

As empresas, em velocidade estonteante, disputam mercados e aceleram mudanças para competir e ganhar o jogo da concorrência. Para isso combinam o domínio da vanguarda tecnológica, a guerra da propaganda cada vez mais sofisticada e a redução de custos laborais. Sindicatos, negociação e acordo coletivo representam obstáculos que devem ser eliminados.

A produtividade se concentra nos países desenvolvidos e nas grandes corporações, que ficam com os poucos e, cada vez mais raros, bons empregos e 
salários. As desigualdades salariais aumentam e as condições de trabalho pioram. O crédito substitui o crescimento dos salários e o endividamento compromete a saúde financeira das famílias.

A legislação trabalhista muda para proteger as empresas, assegurando que as alterações na composição da força de trabalho ocorram sem que haja passivo trabalhista e sem mediação coletiva do sindicato. Cada indivíduo estabelece, de peito aberto e em suposta igualdade de poder e de condições com o empregador, as regras salariais e de condições de trabalho. Formas flexíveis de contrato, jornada e remuneração e as revisão de cada uma com a redução dos direitos, passam a dar às empresas a possibilidade de ajuste estrutural da força de trabalho para promover múltiplas reorganizações com a presença crescente da máquina.

A flexibilidade para as empresas é a insegurança para os trabalhadores, o custo ajustado do trabalho é o arrocho salarial, a competitividade para vencer a concorrência é o estresse e as doenças físicas e mentais, o bom resultado para a empresa é a derrota do trabalhador. A jornada de trabalho das famílias aumenta e a renda familiar cai. Os pais trabalham cada vez mais e os filhos não têm emprego. Os pais se destroem com uma vida profissional precarizada e os filhos se destroem sem perspectiva profissional. Os pais não têm tempo para o presente e os filhos têm um tempo sem futuro. O estresse e as várias formas de doenças emocionais e mentais se expandem na forma de depressão, ansiedade, agressividade, intolerância, apatia. Uma sociedade adoecida trabalha alucinada para produzir uma estúpida riqueza crescentemente concentrada.

A desigualdade aumenta assustadoramente com a concentração da renda e da riqueza. Os ricos pressionam para terem uma menor carga tributária e por um Estado com menor custo social, no que têm sido vitoriosos.

A riqueza concentrada captura os sistemas produtivos dos Estados (estatais) e a riqueza natural, que são privatizados, assim como são transferidos para o setor privado a tarefa de executar os serviços públicos de maneira lucrativa.

Transita-se do direito social universal para a assistência social focalizada; da seguridade para o seguro privado; da proteção garantida para o acesso pelo mérito; do acesso coletivo para o poder de compra de cada indivíduo. Essa lógica dominante é contrária aos valores de solidariedade que instituem os sindicatos, os Estados sociais, as políticas públicas universais, os valores presentes no interesse geral da sociedade e nos fundamentos da coesão social em uma economia de mercado.

Há insatisfação social com os resultados, mas há também a internalização do individualismo exacerbado pelo consumo compulsivo e pelo empreendedorismo libertário de não ter patrão. As fraturas das contradições desses movimentos ficam cada vez mais expostas e a queda da qualidade de vida, o desemprego, o endividamento, tem aberto avenidas para o avanço políticas de extrema direita e autoritárias. Os instrumentos e instituições que promovem a coesão social em uma economia de mercado, por meio da regulação, estão sendo estraçalhados. 
As democracias não têm conseguido gerar a força social capaz de enfrentar essas transformações e dar outro sentido para tudo isso. As instituições do Estado e da vida pública e política não conseguem responder na velocidade de uma comunicação em tempo real e apresentam graves problemas de conteúdo. As democracias correm risco de vida!

A emergência ambiental e a crise do clima estão tomando contornos de catástrofe irreversível. Os impactos nefastos sobre a vida em sociedade e a economia são incalculáveis. Os pobres serão os mais gravemente atingidos. Os trabalhadores sofrerão todos os impactos acrescidos da perda do emprego.

No contexto histórico de estruturação do sistema sindical e de relações do trabalho, as transformações acima indicam que o tempo presente engendra mudanças disruptivas também no sindicalismo, nas formas de contratação coletiva e de construção da proteção laboral e social. Há, de partida, o desafio de compreender o processo de mudança, sua força e dinâmica. $\mathrm{O}$ contexto de complexidades disruptivas coloca tarefas para todo o sistema sindical promover reestruturações que lhe permitam relacionar a dinâmica de mobilização e de representação dos trabalhadores aos novos contextos organizativos do sistema produtivo, às novas formas de contratação e inserção laboral, bem como fazer emergir a agenda de proteção laboral e social demandada pelos trabalhadores que atualmente estão, e no futuro próximo estarão, presentes no mundo do trabalho.

\section{A reforma sindical no Brasil}

Se as mudanças no mundo do trabalho passam cada vez mais a exigir transformações no sistema sindical, há também iniciativas institucionais que recolocam o tema da reforma sindical em debate junto ao Poder Executivo e, principalmente, junto ao Legislativo, mobilizando trabalhadores e empregadores para essa empreitada.

No âmbito do Poder Executivo, o governo instituiu o Conselho Nacional do Trabalho, órgão tripartite (governo, empregadores e trabalhadores) para debater questões sindicais e trabalhistas. O governo afirma que enviará um Projeto de reforma sindical no qual proporá a instituição dos princípios da liberdade sindical (autonomia e não interferência do Estado nas organizações) no primeiro semestre de 2020.

Por outro lado, o assunto da reforma sindical também está ativo do Congresso Nacional. São várias as inciativas de Proposta de Emenda Constitucional (PEC) na Câmara dos Deputados e no Senado Federal.

Os Projetos a seguir indicados estão ativos na Comissão de Constituição e Justiça da Câmara dos Deputados (CCJC), prontos para pauta na Comissão e a proposição sujeita à apreciação do Plenário, em regime de tramitação especial.

Os projetos/propostas tratam da reforma sindical, da liberdade sindical, da unicidade sindical, das contribuições sindicais, do sistema confederativo, das centrais sindicais e da organização no local de trabalho, do número de dirigen- 
tes, da base sindical de representação, de vários aspectos relacionados à negociação coletiva e seus instrumentos, entre inúmeros outros aspectos sindicais e trabalhista, alterando artigos da Constituição Federal como os art. $7^{\circ}, 8^{\circ}, 9^{\circ}$, $11,37,103,114$.

As Propostas de Emenda Constitucional que estão na CCJC são: ${ }^{7}$

PEC 71/1995

PEC 102/1995, apensada à PEC 71/1995.

PEC $29 / 2003$.

PEC 121/2003, apensada à PEC 29/2003.

PEC 314/2004.

PEC 369/2005, apensada à PEC 314/2004.

PEC 426/2005, apensada à PEC 369/2005.

PEC 196/2019, para instalação da Comissão Especial.

Mais recentemente foi apresentada a Propostas de Emenda Constitucional 196/2019, apreciada pela CCJC e encaminhada para a formação de da Comissão Especial para análise de mérito. Essa Comissão Especial está em processo de instalação. ${ }^{8}$

\section{Diretrizes para a reforma sindical no Brasil}

O debate sobre a reforma do sistema sindical e de relações de trabalho tem o desafio de responder a duas ordens de mudanças, a saber: (a) às transformações estruturais e disruptivas no mundo do trabalho promovidas em todo o sistema produtivo, ou seja, criando novas ocupações, de contratação, de subordinação, novos arranjos das empresas, novas relações entre empresas e delas com o Estado; (b) às iniciativas para mudanças na legislação e no regramento que rege o sistema de relações sindicas e de relações do trabalho.

São duas ordens de mudanças que precisam estar articuladas nos projetos que alteram o sistema sindical, assim como sempre se realizará no contexto político situacional presente no país. No caso do Brasil, no contexto de um governo que sistematicamente afirma e atua para restringir o poder dos sindicatos, limitar sua capacidade de contratação, ferir de morte sua capacidade de financiamento. ${ }^{9}$ Se as duas ordens de mudança são imperativos estruturais de grande complexidade e que exigirão respostas da mesma magnitude, o contexto situacional brasileiro reserva uma adversidade dura e uma insegurança quase absoluta quanto aos valores e as intencionalidades que poderão reger os processos legislativos.

Por isso mesmo, o movimento sindical tem procurado estabelecer diálogo de alto nível com o setor empresarial e suas organizações sindicais, bem como com os parlamentares, com vistas a promover um debate legislativo assentado nos desafios acima indicados, assim como promovê-lo em ambiente de diálogo social orientado pelos princípios da boa fé e do interesse de gerar avanços para que o sistema sindical promova relações compatíveis com um desenvolvimento econômico e social de alta qualidade. 
Esse assunto tem conduzido debates acalorados nas bases sindicais que: (a) identificam a adversidade do momento para fazer esse tipo de mudança; (b) a insegurança em alterar nesse contexto uma regra constitucional - o artigo $8^{\circ}$; (c) a necessidade de ter propostas convergentes no contexto do processo legislativo avançar; (d) as diferenças de posicionamento frente ao aspecto da unicidade sindical (um único sindicato na mesma base), da liberdade sindical (possibilidade de pluralidade e pulverização sindical) e das formas de financiamento sindical (somente sócios ou todos os beneficiados pelos acordos e convenções coletivas).

Sistematizamos abaixo aspectos e propostas que estão pautando os debates sindicais desde 2019 e que podem orientar a atuação e intervenção sindical dos trabalhadores.

\section{Fundamentos}

A reestruturação do sistema de representação sindical, se adotar o princípio da liberdade sindical como define a Convenção 87 da OIT, deve ser orientado para um tipo de liberdade de organização que estimule unidade dos trabalhadores e favoreça maior agregação sindical.

Uma reforma deve ser orientada para regras que levem à ampliação da representatividade do sistema sindical brasileiro.

O sistema sindical deve organizar-se para promover relações entre trabalhadores e empregadores no sentido de fortalecer e favorecer a negociação coletiva em todos os níveis e abrangências.

Há que se criar instrumentos e procedimentos que conduzam à solução ágil dos conflitos individuais e coletivos no âmbito trabalhista.

Autonomia para empregadores e trabalhadores instituírem, regularem e manterem a estrutura sindical e o sistema de negociação coletiva, suas regras de funcionamento, a forma de organização sindical e sua sustentação, os critérios e método de aferição da representatividade, a negociação e seus instrumentos de celebração de compromissos e de solução de conflitos.

O sistema sindical e de relações de trabalho deve garantir o direito de negociação coletiva para os servidores públicos no âmbito do direito administrativo.

Um projeto de mudança deve estar lastreado em um plano/processo de transição da atual para a futura estrutura sindical e sistema de negociação coletiva, assentado na cultura e história das organizações e favorecendo o seu engajamento no processo de transformação.

O sindicato deve continuar sendo a base do sistema sindical brasileiro; as federações e confederações são instâncias de agregação de grau superior; as centrais sindicais instâncias de máxima agregação.

A organização no local de trabalho é voluntária e regulada pelas partes interessadas. 


\section{Organização sindical}

Se for adotado a livre associação sindical (alteração do artigo $8^{\circ}$ da Constituição), trabalhadores e empregadores têm autonomia frente ao Estado para se organizarem sindicalmente e estabelecerem regras e procedimentos para as relações de regulação laboral.

As entidades sindicais adquirem personalidade jurídica com o registro civil, sem mais necessidade da autorização do Estado.

O sistema sindical poderá ser constituído por sindicatos, federações, confederações, centrais sindicais e suas organizações intermediárias.

As entidades sindicais serão organizadas por setor ou ramo de atividade econômica e não inferior ao município.

A representação sindical dos trabalhadores nos locais de trabalho é voluntária e esta será regulada entre as partes interessadas.

A contribuição dos sócios às entidades sindicais será definida nos estatutos das entidades sindicais e recolhida em folha de pagamento.

A contribuição negocial (ou contribuição solidária do não sócio) será definida em assembleia e devida por todos os abrangidos pelo instrumento coletivo (sócios e não sócios), observados os limites fixados em lei ou pela entidade nacional de regulação e devida às entidades representativas.

\section{Representatividade}

A representatividade da entidade será aferida observando-se a razão entre o número de sócios efetivamente contribuintes e ativos no âmbito de representação sobre o total de trabalhadores ativos no âmbito de representação.

A entidade mais representativa (ou as mais representativas a partir de uma linha de corte) terão o direito de representação do total de trabalhadores ativos no âmbito da negociação / base de representação.

A representação de todos os trabalhadores abrangidos no âmbito de negociação pela base de representação se dará pelas entidades que obtiverem taxa de representatividade igual ou superior a $\mathrm{X} \%$ no âmbito de representação. $\mathrm{O}$ período de transição deverá prever o escalonamento temporal e progressivo da taxa de representatividade.

Exclusividade: a entidade sindical mais representativa poderá obter a exclusividade de representação ou a exclusividade para o exercício sindical se os trabalhadores abrangidos pela negociação assim deliberarem por maioria em consulta estruturada (plebiscito e outros meios). A exclusividade terá limite temporal e poderá ser renovada.

A representatividade será aferida periodicamente.

\section{Negociação coletiva}

As entidades sindicais passarão a integrar o sistema de negociação coletiva se ao aferirem a representatividade atingirem o percentual mínimo de representatividade. 
Os acordos e convenções, celebrados em negociação por entidades sindicais representativas, depois de aprovados pela maioria dos trabalhadores, atingirão todos os abrangidos no âmbito de representação, independente de filiação sindical.

Quando houver mais de uma entidade representativa no âmbito de representação, a mesa de negociação será única e com a representação unitária de todas as entidades que atingirem a representatividade, sob a coordenação da entidade sindical mais representativa.

Será mantida a vigência dos acordos ou convenções coletivas de trabalho no período das negociações coletivas, em prestígio à boa fé e à segurança jurídica das partes.

Desenvolver sistema de mediação e arbitragem privada e/ou pública, sem poder normativo.

\section{Regulação}

Criar entidade nacional de regulação da estrutura sindical e do sistema de negociação coletiva que terá representação bipartite e paritária (empregadores, trabalhadores).

A entidade nacional de regulação será constituída por um Conselho bipartite e paritário e duas câmaras: de trabalhadores e de empregadores, com atribuições específicas.

Cabe ao ente de regulação: aferir a representatividade (definir método de aferição). Estabelecer normas específicas para o sistema de relações sindicais e de negociação coletiva funcionarem. Regulamentar de maneira complementar o custeio sindical. Criar câmaras de solução de conflitos que envolvam disputas intersindicais. Criar procedimentos para verificar e coibir práticas antissindicais.

Definir forma de financiamento da entidade nacional de regulação ( $\mathrm{x} \% \mathrm{da}$ receita oriunda dos trabalhadores e empregadores).

\section{Servidores Públicos}

O fundamento geral é a Convenção 151 da OIT que trata direito de negociação coletiva para os servidores públicos.

Neste caso, dos servidores públicos, deve-se considerar como referência o Projeto de Lei 397/2015, de autoria do Senador Antônio Anastasia, que "estabelece normas gerais para a negociação coletiva na administração pública direta, nas autarquias e nas fundações públicas dos poderes da União, dos Estados, do Distrito Federal e dos Municípios".

\section{Papel do Estado}

Manter o Conselho Nacional do Trabalho como órgão tripartite de diálogo social para tratar das questões do mundo do trabalho que sejam demandas por qualquer das partes.

Justiça do Trabalho: atuar com mediação e arbitragem, individual ou coletiva, sempre que demandada pelas partes interessadas. 
Promover políticas públicas de emprego, trabalho e renda, de proteção social, laboral e previdenciária.

\section{O que deve constar nas disposições constitucionais transitórias (ADCT)}

Aprovada a PEC, deve ocorrer a instituição do ente bipartite e paritário de regulação em 90 dias.

Preservar, por um período de 3 anos (ou X anos), as prerrogativas das atuais entidades sindicais para que se prepararem para a primeira mensuração da representatividade.

\section{Conclusão}

As mudanças no mundo do trabalho que estão em curso alteram os empregos, as ocupações, os postos de trabalho, a dinâmica laboral, as formas de contratação, jornada e condições de trabalho, entre inúmeros outros aspectos. Iniciativas dos poderes Executivo e Legislativo indicam disposição para alterar as regras constitucionais e normativas do sistema sindical brasileiro. A agenda da reforma sindical está em pauta.

Há posicionamento diversos no mundo sindical dos trabalhadores. Há aqueles que defendem que se deve preservar as atuais regras e há aqueles que concordam com mudanças. Todos querem um sindicalismo ativo e representativo e com negociações estruturadas. Todos consideram que o momento é de grande adversidade para tratar do tema.

De todo modo, mesmo que não se promovam alterações nos marcos normativos legais, há que realizar uma profunda reestruturação sindical para que a organização dos trabalhadores se coloque coetânea ao novo mundo do trabalho que irrompe nas bases das transformações do sistema produtivo. Representar todos os trabalhadores, com organizações estruturadas de modo a favorecer uma agregação ampliada da representação (setor ou ramo de atividade) e voltadas para práticas de cooperação.

Nesse caso ainda, poder-se-ia avançar para o desenvolvimento de um sistema autônomo e efetivo de autorregulação entre trabalhadores e empregadores, que fosse suporte para a reestruturação sindical do sistema de relações de trabalho e a solução dos conflitos por meio de instrumentos criados pelas partes.

Entretanto, se o processo legislativo for em frente, há que ter propostas para serem colocadas em debate. O Congresso Nacional poderia ser palco de um pacto entre trabalhadores, empregadores e organizações do Estado, que passariam a regular de maneira autônoma as relações laborais e sindicais.

Notas

l Esse Fórum se reuniu de setembro a dezembro de 1993 na cidade do Rio de Janeiro e era composto por 11 representantes dos trabalhadores, 11 dos empregadores e 11 de órgão do Estado e sociedade civil. Os debates e as conclusões estão registrados na publicação do Ministério do Trabalho, "Fórum Nacional sobre Contrato Coletivo e Relações de Trabalho no Brasil” (Brasil, 1994). 
2 A PEC 369/2005 está disponível no site da Câmara dos Deputados no seguinte endereço eletrônico: <https://www.camara.leg.br/proposicoesWeb/fichadetramitacao?idP roposicao $=277153>$.

3 Esses e outros aspectos foram questionados com Ações de Inconstitucionalidade junto ao Supremo Tribunal Federal, ainda não julgadas.

4 Para uma análise detalhada do conteúdo da reforma recomendam-se as Notas Técnicas e demais publicações do Dieese, disponíveis em <www.dieese.org.br>, em especial a Nota Técnica 178 "A reforma trabalhista e os impactos para as relações de trabalho no Brasil" e a Nota Técnica 179 "Relações de trabalho sem proteção: de volta ao período anterior a 1930?”. No site do Dieese estão disponíveis também textos, apresentações e vídeos sobre o assunto. Sobre terceirização, entre outros estudos produzidos pelo Dieese, destaca-se a Nota Técnica 172 "Terceirização e precarização das condições de trabalho". Também se indica a publicação do DIAP "Reforma Trabalhista e seus reflexos sobre os trabalhadores e suas entidades representativas", publicada pelo Departamento Intersindical de Assessoria Parlamentar, disponível em <www.diap.org.br> .

5 Fontes e metodologia do estudo: As principais fontes de informação são as bases de dados da OIT EPLex e Natlex, as mais abrangentes sobre o assunto segundo os autores. $\mathrm{O}$ apanhado distingue as mudanças nas seguintes áreas (subdomínios) da legislação: contratos permanentes de trabalho; contratos temporários de trabalho; outras formas de emprego (teletrabalho, dependente self-employees); instituições da negociação coletiva; demissões coletivas; e jornada de trabalho. Assim, no caso de uma reforma abrangente, como a espanhola de 2012, os autores identificaram 18 alterações (segundo o subdomínio). A estas mudanças denominam, no estudo, "reforma". Segundo os autores, esse procedimento pode levar a um número elevado de mudanças em determinado país sem, contudo, refletir a importância dessas. Para minimizar o problema, classificam todas as mudanças segundo três variáveis zero ou um (dummies): o sentido da intervenção (se aumenta ou diminui a legislação); a temporalidade da intervenção (se em bases permanentes ou temporárias); e se a sua cobertura / população alvo é parcial ou abrange toda a população.

6 Como variáveis explicativas, os autores utilizam: a) para o ambiente macroeconômico, a diferença entre a taxa de variação do PIB e sua taxa média de variação em 5 anos, centrada no ano corrente; b) para a situação fiscal, uma variável indicando se há ou não um processo de consolidação fiscal em curso; c) variável indicando a presença ou não de um regime de câmbio fixo ( ou pertencimento a uma união monetária); d) PIB per capita como forma de captar as especificidades de cada país; e) duas variáveis, para captar a presença de ano eleitoral e ano pós eleitoral; f) uma variável para captar a orientação política do governo; g) outras variáveis menos relevantes.

7 Indicamos o aplicativo Infoleg, Câmara dos Deputados, por meio do qual se pode acessar todos os projetos abaixo, mapeando seu processo legislativo e situação atual. Disponível em: <https://www2.camara.leg.br/infoleg/aplicativo/>.

$8 \mathrm{Na}$ primeira quinzena de março a maioria dos Partidos Políticos já haviam indicado os parlamentares que irão compor a referida Comissão Especial, o que aponta a possibilidade de instalação dessa Comissão na segunda quinzena do mês. Os trabalhos dessa Comissão duram de 10 a 40 sessões (em torno de 3 meses), cujo Relatório, quando aprovado na Comissão Especial, segue para duas votações do Plenário da Câmara dos Deputados, seguindo depois para trâmite semelhante no Senado Federal. 
9 Dois exemplos recentes desse tipo de inciativa: em março de 2019 o governo federal editou a Medida Provisória (MP) 873/2019 que restringiu o financiamento sindical e as formas de recolhimento em folha de pagamento. Essa MP caducou, mas seus efeitos práticos continuam a atingir os sindicatos. A MP 905/2019, em vigor até meados de abril deste ano, e em debate no Congresso Nacional, altera inúmeros aspectos da regulação do trabalho e tira poder dos sindicatos na negociação coletiva da jornada de trabalho, da participação nos lucros e resultados, entre outros. Isso sem citar as falas de ministros e do próprio presidente que externam sua visão sobre os sindicatos.

\section{Referência}

BRASIL. Ministério do Trabalho, Fórum Nacional sobve Contrato Coletivo e Relações de Trabalho no Brasil. Brasília, 1994. 445p.

RESUMO - A reforma sindical e do sistema de relações de trabalho está novamente em pauta no Brasil. Este texto apresenta um breve histórico e o contexto atual dos debates, além de propor algumas diretrizes e aspectos que deveriam ser considerados para as mudanças..

PALAVRAS-CHAVE: Sindicalismo, Reforma sindical, Sistema de relações do trabalho, Legislação trabalhista

ABSTRACT - Reform of trade unions and labor relations are again on the agenda in Brazil. The aim of this article is to present a brief history and the current context of the debate, and to propose some guidelines and aspects that should be considered to implement the changes.

KEYWORDS: Trade unionism, Trade union reform, Labor relations system, Labor law.

Clemente Ganz Lúcio é sociólogo, professor, consultor, foi diretor técnico do Departamento Intersindical de Estatística e Estudos Socioeconômicos de 2004-2019. Técnico do Dieese desde 1984. @-clemente@dieese.org.br /

https://orcid.org/0000-0001-9718-0703

Recebido em 9.3.2020 e aceito em 11.3.2020.

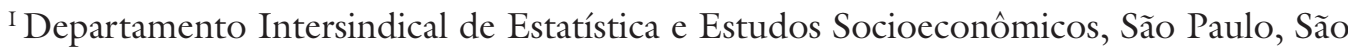
Paulo, Brasil. 